-

\title{
Mobbing in Company: Levels and Typology
}

\author{
Beno Arnejčič
}

\author{
University of Primorska, Faculty of Education, Cankarjeva 5, 6000 Koper \\ beno.arnejcic@pef.upr.si
}

\begin{abstract}
Background and purpose: The individual is exposed to ever more covert psychological violence or mobbing in workplace within companies. The aim of this study is to analyse the level and the types of psychological violence within a company in which the individual works in their daily lives.

Design/Methodology/Approach: Using systematic method current mobbing literature reviews were analysed. Based on a review and analysis of the literature, we recognised increasing amounts of workplace bullying. Then we used and extended Dilts' model and created a model in which we portrayed the different levels and types of bullying in a company. The presented model is a tool for identifying workplace violence within the company.

Results: At the company environment level, there is much bullying associated with social-demographic characteristics and working conditions. At the level of individual behaviour, the type of mobbing exists that is associated with the company's leadership styles. At the level of professional qualifications, a lack of confidence causes mobbing. At the level of values and beliefs, mobbing is present in attitudes and behavioural intentions. At the level of identity, we can observe mobbing according to sexual identity. At the level of organizational culture, we can recognize a type of mobbing called 'obsessive dedication' to working efficiency and organizational silence.

Conclusion: Based on the analysis of selected literature we exposed a range of types and levels of mobbing in company. The expanded Model on levels of mobbing in companies provides a framework for collecting information. The user can identify workplace violence and each strategic organizational level in the work organization
\end{abstract}

Keywords: bullying; mobbing typology within the company; levels of mobbing in the workplace

\section{Introduction}

The individual is exposed to more and more covert psychological violence in the workplace. The most common forms of psychological violence in the workplace today are social exclusion (ostracism), ridicule, envy behaviour, imposed prohibitions and demands, requiring obedience at all costs and suffering humiliation (Cacioppo and William, 2008). All these forms of mobbing are becoming more and more complex. The complexity of the psychological violence can explain the degree of mistreatment in arranging the levels of the introduced model and mobbing of individuals within the organization.

This article was written using the systematic method of scientific literature analysis, common and logical analysis, and comparison and generalization methods on the subject of mobbing between the years 2012 and 2016. The objective of this study is to present the distribution of the types of psychological violence within the company in which the individual works, during his everyday life in Model on levels of mobbing in companies. The Model is based on an analysis of selected and current literature about mobbing in companies and an observation of the internal structure of individual mobbing threats.

The research questions are as follows:

How examination of selected scientific literature and definitions of mobbing allows a better overview of the types of psychological violence in the company?

What type of psychological violence against individuals corresponds to a certain level of mobbing in a company? 


\section{Mobbing within the company and related concepts}

In psychological violence or bullying talk, groups of individuals disorganized and uncontrollably implemented verbally surreptitious violence, which caused mental suffering to the victim. (Leymann, 1990). The US National Survey 2014 defines mobbing as follows: mobbing is repetitive, dangerous, humiliating, intimidating psychological abuse at work, various patterns of sabotage in the workplace, as well as verbal abuse. Mobbing and various forms of intimidation in the workplace in the US is the new "epidemic". In their desire for economic survival in the labour market, many US employers psychologically abuse their workers. Workers are often helpless victims due to the lack of legislation in the field of protection against mobbing. Employers, therefore, do not assume responsibility for the prevention and elimination of mobbing in the workplace (WBI- USA, 2014).

Psychological violence is a form of behaviour in which ignorance, slander or malicious rumours, insulting the employee, feelings of guilt, spreading fear about loss of employment, imposed prohibitions and demands, jealous behaviour, victimization due to religious and sexual orientation, sexual harassment and physical assault all stand out. All these forms of psychological violence in the workplace can be called 'mobbing'. Psychological violence is becoming pathological and the main problem of interpersonal relations in the workplace and in the civil environment (Laymann, 2012). Depending on the frequency of the occurrences, researchers can highlight two types of maltreatment in the workplace:

- Vertical wall mobbing: when an individual defames the subordinate employee. Control technology allows him to do this in a way that defames several individuals in sequence (serial mobbing) or planned defamation (strategic mobbing or bossing), but in rare cases, a group of subordinates defames the person.

- Horizontal mobbing: this is psychological violence in the organization, which often occurs in a group, when employees direct their violence against certain members of the collective. They mock, disseminate and make other malicious rumours about him (Arnejčič, 2014).

\subsection{The concept of adverse psychologi- cal violence within a company.}

The concept of mobbing based on broader range of actual scientific literature and research. Brousse, Fontana and Ouchchane (2008) observed psychopathology among populations of targets of workplace bullying. Horvat and Pagon (2012) made research about attitudes toward workplace mobbing in Slovenia. Manotas (2015) made analysis about mobbing in Higher Educational Institution. Picakciefe, Acar, Colak and Kilic (2015) highlighted socio-demographic characteristics of mobbing. Qureshi, Iftikhar and Janjua (2015) made empirical investigation of mobbing, stress and employees' behavior at work place. Waschgler, Ruiz-Hernández and Llor-Esteban (2013) observed bullying in nursing in the context of the hospital aggressive behaviour scale.

Zimbardo (2007) states that the relations between people who lack confidence are dominated by egoistic individuals, some of which have the power of management and administration in their hands, speaking from a position of apparent authority, which provides them with the opportunity to confer adverse effects on others. We call it the passion to dominate, where leaders influence others to make them obedient. The subconscious desire of an individual to be adopted, to understand and comprehend the desires and aspirations, is actually conformism and an attempt to influence others. Against these undesired methods of influence, which inevitably lead to psychological violence at the workplace, we can take these three measures: investing in individual development and in strengthening our self-esteem (self-awareness); by understanding the sensitivity of our personal situation (situational sensitivity), and by becoming more astute (street wise). These three methods defined by Zimbardo (2007) the key to our personal resistance against the unwanted influence of other individuals and groups.

Mobbing is a psychosocial risk that directs the worker to a complete mental and physical collapse and may cause a 'burnout'. According to reports, psychosocial risks in the workplace from 2012, a psychological burnout is notable and typically occurs in Slovenian teachers. This usually occurs in conjunction with difficulty in concentration and a considerable loss of interest in everyday activities. Psychological burnout is the result of psychological violence in the workplace with negative effects on the health of the worker. Psychological burnout is a threat that is significantly associated with violence in the workplace (Eurofound, 2009). The worker needs special training to recognize signs of mental exhaustion. Recognition includes the realization that we simply cannot do everything that is requested from us, and that we must be attentive to the valuable signals that our body gives us. The best personal protection against burnout is the ability to say "no" without any feeling of guilt.

The consequence of psychological terror in a company is stress in employees. In the workplace, senior executives and managers are becoming more aware of stress and employers recognize the psychological tension in employees (Lahad, 1993). Stress among company employees intensifies conflicts in interpersonal relationships in the company. Costs incurred resulting from conflicting relationships 
can cost the company half of the annual profits (Sunderland, 2010). As soon as an individual begins to fail, the physical, mental, or psychological work-efficiency drops, causing a dangerous escalation of errors in the work process, a negative impact on work performance, and paralysing the individual's ability to respond rationally. Stress usually causes anxiety. The pituitary gland in the human brain sends the hormone corticotrophin along the adrenal glands. The body then responds with increased secretion of the stress hormone cortisol. Due to the high levels of cortisol, the individual feels defenceless, miserable and afraid: His thoughts, feelings and perceptions of stress are characterized by a sense of threat and fear. Everything the individual has to do at that moment is much too difficult (Sunderland, 2010). When we are stressed, we react primarily with our emotions so that our power of words is limited and subordinate (Cacioppo and William, 2008).

In cases where stress is caused by objects, such as a car alarm which awakens us during the night, this leads to a release of the hormone cortisol, for which the body requires about 40 minutes to recover. In fights between individuals, there is a different kind of stress caused by personal conflict. In this case, cortisol remains in the body for much longer; at least an hour and a half (Sunderland, 2010).

The concept of ostracism or social exclusion has the most significant negative consequences of covert psychological functioning. The definition of ostracism has changed over the years. At first, ostracism meant the process of social rejection or exclusion (Wang 2013). Then Sommer Williams, Ciarocco and Baumeister in 2001 revealed that the word ostracism meant deliberately ignoring or excluding an individual (Williams and Nida, 2011). Ostracism is now used to mean exclusion, rejection or ignoring of an individual or a group of other individuals or groups, with the ability to preclude the establishment of a contact or an existing positive interpersonal relationship, personal or work relationship, favourite status at home or at work. Research has shown that ostracism is a specific form of interpersonal conflict, which harms the basic human needs such as belonging, control, self-esteem and the importance of existence. (Gruter and Masters, 1986; Williams, 2011; Goodacre and Zadro 2010)

Ignorance is covertly present in the group dynamics of every company. The management style of a professional leader is affected by the degree of ignorance in the company. The Head of the working collective who restricts ignorance establishes a good relationship with employees. On the contrary, a leader who builds relations on obedience and ignorance, charges up negative feelings in employees. This often strengthens emotional reactions such as shock, horror, surprise, confusion and disorientation, as well as physiological reactions (discomfort in the stomach and chest and the need to urinate) (Williams, 2001).

Ostracism is conceptually and empirically distinct from mobbing. Studies have shown that employees have a strong need to belong to their organization. Researchers have studied the correlation frequency and impact of ostracism and mobbing in organizations. Most of the staff perceived ostracism compared with mobbing as a more socially acceptable (and less psychologically damaging) phenomenon. However, it is less likely that the law shall prohibit this in working organizations. In the next study, researchers found ostracism in company more harmful than mobbing. The effect of ostracism in employees is reflected in becoming unwell and is connected to his/ her views in relation to work and a sense of belonging. The study about the comparative effects of ostracism and harassment at work found that ostracism and mobbing is associated with a sense of belonging to the working organization (O’Reilly et al. 2014).

\section{Types and levels of mobbing in the company}

\subsection{An analysis of the level of mobbing in the workplace and the expanded Model of mobbing: the levels and types of mobbing within a company}

The model levels and types of mobbing within the company are based on Dilt's pyramid (Dilts, 1999). The model is structured on six levels and is shaped like a pyramid, based on detailed analysis of current literature on the topic of mobbing from 2012 - 2016. Each level in the pyramid corresponds to a certain psychological structure of the individual within the organization. Each level contains the categories of mobbing within the organization and the internal psychological structure of an individual who is exposed to psychological violence. The width and the gradual reduction of the hierarchical pyramid represents the highest level of abstraction, the power of the unconscious in the individual and the company (individual and 'collective subconscious' of the individual), and the impact of a threat to the individual. Dilt's pyramid is a model of the system used to apply individual perceptions of reality. The expanded model is a systematically regulated model applied to an individual's perception of reality in the company and the perception of the reality of mobbing at company level as an institution and at social group level. The reason for its expansion is a complex perception of mobbing at the individual level, at the company level and at group and social level.

In chapters from 3.1.1 and 3.1.2 we described and analysed each level of mobbing according to the inner psychological structure of the individual. In describing the structure, we took into consideration and analysed the relevant literature on mobbing in companies, and then made the selection. 


\subsubsection{Mobbing on the first three levels: environmental, behavioural, and the level of individual skills}

The first level of the pyramid is mobbing at the level of the environment. Harassment or mobbing in the workplace is associated with different circumstances. Among them are the most typical ones that are related to the health of individuals, socio-demographic circumstances and those related to working conditions.

In the city of Mugla in Turkey, a survey was carried out on mobbing in medical staff-workers and in emergency medical assistance. The survey involved 130 volunteers (91.5\% of responses were considered). The study looked at the link between socio-demographic characteristics, working conditions and the level of mobbing. The findings were as follows: The maximum frequency of mobbing against workers over married workers, especially against those who were employees of the organization for more than 16 years. This is then followed by mobbing against those individuals who react to psychological harassment in the workplace. Workers in emergency medical aid have great tolerance for mobbing (Picakciefe et al., 2015).

In the eighties, ecologically-conscious psychologists, sociologists and philosophers started to introduce a new model of social awareness of the environment (Trstenjak, 1984). Executives or employees of the company should pay more attention to the emotional states and factors in individuals. Emotional agitation directs workers against each other, causing feelings of guilt and anxiety which provokes the situation increases the fear of losing employment in uncertain times. Negative psychological feelings, due to mobbing may be transferred by employees to their private lives in their homes and relationships.

Often, mobbing is focused towards individual negative emotions (fear, disgust and sadness) or towards the accompanying negative emotions that are always in the background of basic emotions (distress, agitation, irritability) (Demasio, 2008). Mobbing of individuals at work at the environment level also covers the ecology of consciousness (Kirn, 2004). The ecologically minded individual is aware that a change in the working environment may reflect a change in the whole system. Those who conduct psychological harassment in the workplace (employers, leaders, heads, individuals or even a group) should be aware that this causes negative, even pathological consequences for the entire system, - companies, organizations i.e. working environment. In the modern world, where the production of artificial fear is enormous, the individual, as a one-man-band or as a member of a larger or smaller group, experiences a variety of attempts of undesirable influence of the environment every day (from other individuals or groups). This is especially true in the workplace, where the person spends most of his time.

At this level, we looked at all kinds of mobbing associ- ated with the behaviour of the individual in the company. The types are as follows: Excommunication or deliberate exclusion and isolation of the individual from communication and information; an undesired influence over workers from managers; the demand of obedience at all costs, or degrading behaviour.

The individual should develop behavioural self-defence mechanisms from mobbing in the workplace, in a way that the following questions should be asked: What do I have to do? How should I respond in the workplace when experiencing bullying? How should I behave in order to endure the bullying? What kind of communication may trigger violent responses by other workers or leaders? The purpose of my message is the response that you give back as a return message, including behaviour and communication towards others in the organization. This includes all verbal and non-verbal communication (Dilts, 1990).

Mobbing at the level of individual behaviour can be observed in the relationship between superiors and subordinates in the company. The study assessed the incidence of mobbing in relation to the different management styles and positions in relation to the work. The results confirmed the predictions regarding the effects of leadership types on mobbing from Supervisors (i.e., downward mobbing). Transformational and transactional leadership have reduced the likelihood of mobbing, whereas authoritarian leadership has grown (Ertureten, 2013).

Unwanted influences in modern society, institutions and externally, prey primarily on individuals with low self-esteem and those who are intimidated using accurately calibrated techniques to make them feel insecure. As a result, many individuals try to defend against unwanted influences by shrinking their relationships with others to a minimum, almost with no-attitude and ignorance. This is actually the most unfortunate way, as the individual is led towards failure, which stems from his inherent weakness (Arnejčič, 2008).

Mobbing of individuals at the level of his skills and abilities covers different psychological states and individual strategies. An employee's dismissal from work affects the ability of the individual and lowers his self-esteem. The results are visible at the system level or at company level. A change in behaviour in one part of the system is also reflected in a change of behaviour of individuals in other parts of the system. Mobbing of individuals at capability levels is implemented in the form of imposing prohibitions and demands, which start with the word "No" or "You need to be... like...", with added unrealistic deadlines for tasks and gossip. Those individuals risk their reputation and social position if they are to reveal irregularities in their company organization. Do's and Don'ts are characterized by the linguistic patterns of superiors in a company or the collective, who use victimisation as a weapon against those who are different. Typical stereotypes are: “Don't trust; Don't show your emotions; Don't stand out; 
Don't make mistakes; Don't show any distress". Typical commands by leaders are: "Do it all!; Work faster!; This will be hard work!; Keep your problems to yourself!; Give me $100 \%$ !"'. One can protect against the negative effects of mobbing by trying to answer the following questions: What should I do so that I feel OK? How do I develop an appropriate strategy to deal with this? What changes in my personal state may affect my work situation at the company?

The individual's social and other skills have an important role in protecting against the various forms of mobbing in the company. At the University of Victoria in Canada, a study was made on the role of social skills and workers' social situation in the company. Differences in individuals' skills caused different levels of response to the existing social order. Social interaction skills and the social situation of the worker allow different types or categories of reflection, which is very important for the stability of the institution and changes in the company. If an individual within the organization is sufficiently responsive, then changes are visible where others do not see them. These types of individuals adapt more easily to changes in the company. These authors designate corporate social skills (Suddaby, Vials, and Gendron, 2016).

Mobbing in the company threatens the health of the individual and the collective. One of the groups most at risk are nurses. A team of researchers from the University of Erzurum in Turkey carried out an empirical study on the impact of assertiveness training on mobbing. The study included 218 nurses. The first group were nurses involved in an assertiveness training program. The second group was not included in the said training. The most important outcome of the study was that assertiveness training was effective in reducing mobbing in the work organization. It is necessary to establish an adequate training program, which supports the personal development of nurses, providing advice and support to victims of mobbing. The results are as follows: Mobbing among nurses is very widespread and most nurses stand up to this phenomenon. Medical nurses who have received assertiveness training have developed self-confidence and new social skills. Training of assertiveness increases self-confidence and improves nurses' skills in resisting mobbing in the workplace. (Karakas and Okanli, 2015).

\subsubsection{Mobbing on the other three levels: beliefs and values, individual indentity and the organizational culture}

The individual enters into a company with their beliefs and values, which are harmonised during the work process, with the beliefs and values of employees and especially with the beliefs and values of the company. Upon entering the organisation, there may be a collision and conflict of values between the individual and the company. This leads to mobbing or harassment due to values and beliefs and is directed against the motivation of the individual to work. It covers jealous behaviour, hypocrisy, one-way communication in the company (monologue); limiting open communication with co-workers, religious victimization and sexual harassment in the workplace. Envy is also developed in people who are not sufficiently exposed to the internal sense of wealth and power. Therefore, the surge of generosity is often followed by the excessive need for recognition and gratitude (Klein, 1997). Conversation or discussion may take place on condition that the interlocutors are tolerant and ready to listen to the critical views of another. Conversational conflict is a monologue. Here, the monologue is perceived as being more expressive than speech itself, whether out loud or in silence. Usually, performances of monologues or narratives denote individuals who are not willing to listen to the initiator, for various reasons (Arnejčič, 2014).

Mobbing in the workplace also includes different views and behavioural purposes associated with different behaviours suggestive of maltreatment. Studies made by Slovenian public research organizations showed differences in mobbing experiences in the workplace. The views of those questioned largely depended on their beliefs about the attitudes of employees. Employees were less willing to report mobbing, and employees spoke of lenient disciplinary measures and the lack of adequate organizational rules. This creates favourable conditions for the development of mobbing in Slovenian public research organizations (Horvat and Pagon 2012). Researchers saw some forms of mobbing at the level of beliefs, which form in different positions, resulting in a reduction of communication between co-workers.

Current research on mobbing in the field of organizational psychology addresses issues such as prosperity, harmonious relations, and the welfare of the individual in work organization. The following are a positive influence on the attitude towards employees and the implementation of work in the company. Prosperity and harmony are the desired values of a working organization. The company should ensure an employee such work that he is satisfied with and consequently becomes more productive. Only happy workers can be productive. Many workers, due to the ruthlessness of the owners of the capital, develop an obsessive passion to work. Obsessive passion is positively associated with a high level of burnout. If workers are hardworking and have an obsessively strong passion to work, they are less able to recognize and change their behaviour in the workplace. This attitude impairs working relationships and reduces collaboration among employees. Cooperation and good relations with such individuals become a risk. (Birkeland, 2014).

Our behaviour is linked to the activity that is important to us at any moment. This may be personal values, ideals, standards, principles, and so forth, which become the ba- 
sis for resistance against the unwanted effects of maltreatment. A mistreated person can protect himself from the negative effects by asking the question: What is important to me when I am being bullied? 'Important' means what an individual classes as maltreatment and what to do in that moment when he experiences bullying at work? What are the risks when I am exposed to mobbing? Answers to these questions lead to reframing the context of the experience of maltreatment, or by changing negative beliefs into positive. It is important that the answers to the questions are positive.

Examples: "I am safe!; I am OK!; I can be happy!; I can be successful!; I can be calm!". Some individuals, however, by rebellion and perseverance, are able to find the inner strength to resist using their own psychic sources.

An individual in the working process usually asks himor herself the following questions: What do I think about myself? What do I believe other people think about me? What do others think of me? The latter questions constitute the internal structure of identity or self-esteem of individuals working in a company.

Replies to these questions form the internal structure of threats of maltreatment in a company. Types of workplace bullying are: deliberately influencing the worker's self-esteem; ridiculing and humiliating made by colleagues and management, and mocking behaviour. The employee is always asking how much inner strength is needed to withstand the psychological pressures.

Psychologists are convinced that pathologic and violent personalities are often attracted to leadership positions. It is therefore of paramount importance that these people may be recognized and eliminated already in the process of psychological selection upon entry to the organization and collective. The nature of duties should be established in order to strengthen empathy, cooperation and collaborative conversation, personalities with developed heart culture, an open mind, courage, professional awareness and trust in an active relationship with colleagues.

In the light of the individual's identity within the organization, which includes trust to carry out certain work and trust in building relationships, are some interesting results of studies on the phenomenon of mobbing within Universities. Researchers assumed that the highest level of education ensures a high degree of trust in individuals who we are working with. Research proves that this assumption does not hold. Mobbing within the University organisation often occurs when an individual demonstrates a strong personality, not allowing any kind of manipulation and with an organised family life and a happy and confident personality. This type of personality arouses jealous behaviour from colleagues. In this instance, mobbing is influenced by the age difference between colleagues and co-workers, their work experience and the differences in the manner they react to the problem. Some individuals exhibit greater personal sensitivity under difficult working conditions and react more dramatically. The key variable, which describes the conditions associated with mobbing, is emotional intelligence (Manotas, 2015).

In Anatolia, Turkey, a study was conducted in which they examined the relationship between mobbing and the symptoms of depression in secondary vocational school students, regardless of gender. The purpose of the study was to determine the levels at which symptoms of depression occur. Symptoms of depression include intense sadness, hopelessness, anxiety, slowed thinking, talking and movements, stagnation, worthlessness, meanness, weakness, reluctance, and slowing down of physiological functions. In school, more than two-thirds of men in comparison to women were exposed to mobbing. Gossip and jokes were used against females and they were more exposed to social exclusion. The study found that there was a high level of interaction between students, regardless of gender, exposed to intimidation. However, there was no statistical correlation between gender of students and the onset of symptoms of depression. Of the students exposed to mobbing, the statistical differences between the rates of depressive symptoms were not observed (Akinci et al., 2015)

Organisational culture in individual parts of the organization includes the social inclusion of individuals in a working relationship, a wider integration of the individual into different levels of the company, and coherence and belonging to the company that has a positive working climate, which, in turn strengthens health. Organizations or companies that are not 'healthy' carry out intimidation at the highest level, i.e. at the level of organizational culture. This type of mobbing is carried so that there is usually a very bad working atmosphere among employees. A bad working atmosphere releases fear which causes silence so that the majority of employees prefer to remain silent rather than talk about mobbing. There are different factors for such behaviour in a company: fear of losing their job or not being able to have the opportunity to state their ideas to the management.

Two new phenomena are present: turnover intention and organizational silence. Turnover intention is the chance of employees leaving their job or organization of their own free will. Increasing the turnover rate increases job absence. Organizational silence is the term that describes individual behaviour where persons do not express their thoughts, opinions or suggestions in order to improve company activities. Current research shows that when we compare organizational silence and mobbing, mobbing has a stronger effect on employees' turnover intentions. Finally, when all factors are taken into consideration, mobbing plays only a partial mediation role. This study presents large amounts of fundamental evidence of mobbing in the workplace as well, as it reveals a scope with regard to its moderating effect on the relation of silence behaviour and turnover intention manners of employees (Elçi, 2014).

Bullying at the level of organizational culture is divid- 
ed into the following types: distrust of superiors by employees and mistrust among colleagues; organizational silence; turnover intention; social exclusion (ostracism); collective victimization, plots or intentionally malevolent rumours or conspiracies in order to make bribery of votes, in favour of the management of the company and intentionally influencing the individuals suffering.

The consequences of mobbing at the level of organizational culture are associated with the deterioration of the mental health of company employees. European studies have shown that there are many employees with mental health problems. Experts merged ten of the most important emerging risks of work and the effects of work on health, into five areas:

1. New types of employment contracts and precarious employment.

2. An aging workforce.

3. Increased work intensity.

4. Great emotional stress in the workplace.

5. Lack of reconciliation of work and family life (Facts, 2007).
The causes of workplace bullying most often lie with the management. The most frequently hostile actions have been an excessive workload; gossip and rumours; withholding of information relating to work; assuming responsibility; insults; humiliation; ignorance (Garlic, et. al., 2009).

In the work environment, due to the growing desire of owners of capital to accumulate wealth the worker spends more and more time, free of charge, as well. Trstenjak (1984) already in the 80's pointed out the risks in the workplace arising from distracting human consciousness and awareness in this area. He pointed out the research made by psychologist Baker on behavioural settings. Trstenjak criticized Baker, saying that they are not interested in social interaction and interpersonal relations. In the foreground only institutional behaviour is seen, by regulating certain cultural norms. This was for Trstenjak only one component of the ecological debates in social psychology, joined by research into individual attitudes towards cultural environment, bearing in mind the individual as a role holder in society and ad-hoc cooperation with groups

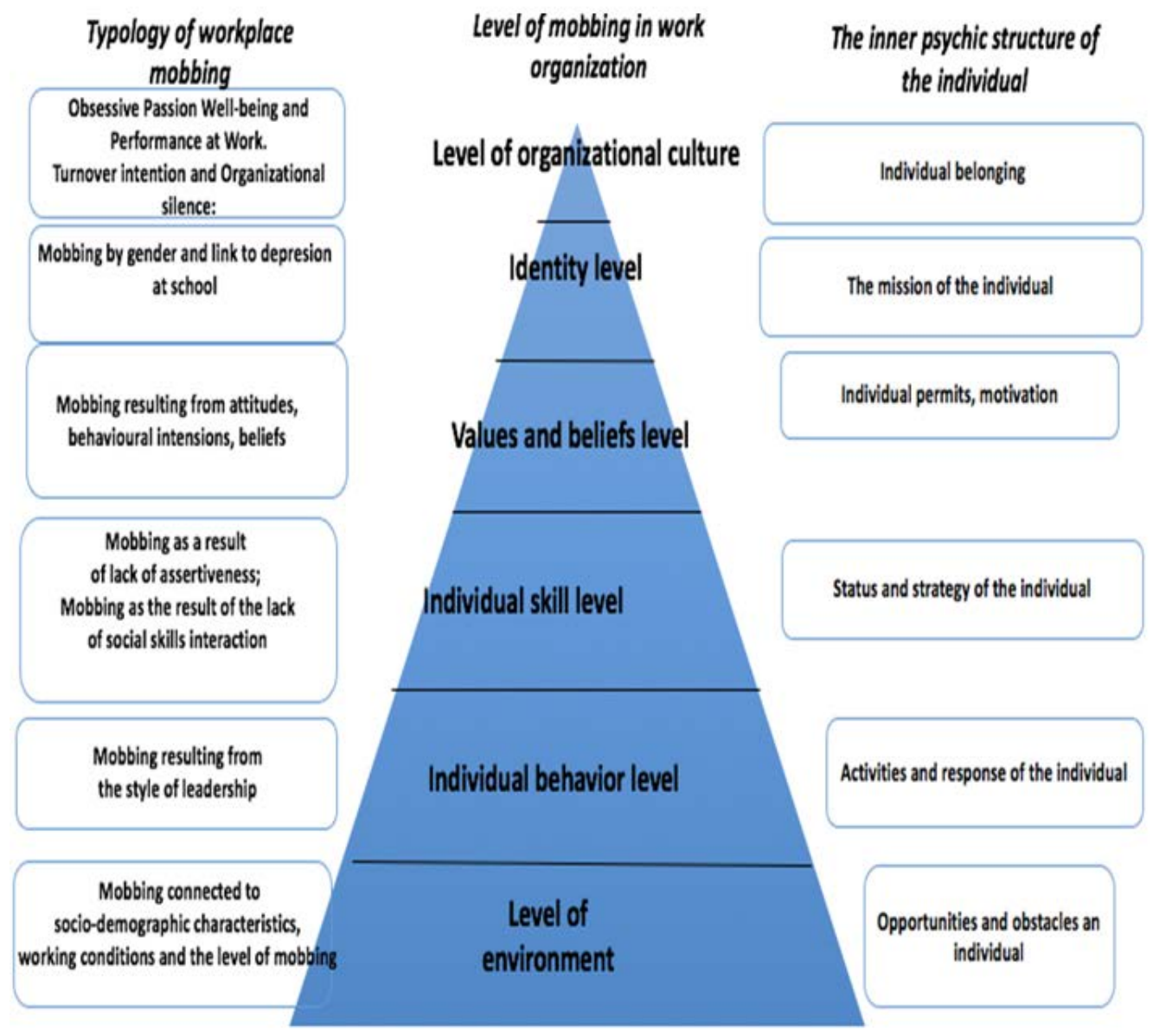

Figure 1: Model of mobbing levels and types in the company, adapted and expanded according to Dilts, 1999) 
(Trstenjak 1984: 101). That paradigm of social psychology is not outdated, but increasingly more topical. By simply raising awareness based on enhanced self-esteem protects the individual against unwanted effects of psychological violence in the workplace.

In designing the expanded model, we took into consideration Leymann's forms (1993) of psychological violence within an organization, which is divided into five types of attacks:

1. Attacks against expression and communication (limiting the chances to express and communicate with the management, disrupting speech, criticizing the work, threats...).

2. Attacks which threaten the social contacts of the victim (no -one wants to talk the victim anymore or colleagues are prohibited from communicating with the victim, the victim is isolated in the working premises away from staff, general ignoring of victims...).

3. Attacks that endanger the personal reputation of the victim (defamation, ridiculing the victim, spreading rumours, ridiculing the victim's physical defects...)

4. Attacks against the quality of the job (the victim does not receive any more tasks, obtains meaningless tasks, tasks which are below or above qualification levels, allocation of too many tasks...)

5. Attacks against health (being allocated harmful tasks, threats of physical violence, physical abuse...) (Leymann, 1993, and 1996).

\subsection{Current mobbing literature reviews and the criteria for model design}

Table 1 summarises is the result of the analysis of relevant and actual scientific literature on mobbing in the company. Below we present the reviews of mobbing in the company. At each level, the authors found very specific characteristics of human behaviour. We have selected and classified the articles depending on the level and type of mobbing which occur in the company. In the third column, we noted the proper authors that deal with mobbing.

\section{Conclusion}

We presented model levels and types of mobbing in the company into six levels, in the shape of a pyramid. The levels are arranged in hierarchical order. The model provides a framework for collecting information and the user can identify workplace violence and each strategic organizational level in the work organization. Each level contains the categories of abuse in the organization and the internal psychological structure of an individual who is exposed to psychological violence. The width tapers down to the level of organizational culture. The width of the pyramid in the hierarchical model gradually narrows towards the top of the pyramid, representing the level of abstraction or the power of the subconscious (individual and collective subconscious of the individual) or the impact of the threat

Table 1: Current mobbing literature reviews

\begin{tabular}{|c|c|c|}
\hline $\begin{array}{l}\text { Level of } \\
\text { mobbing in } \\
\text { company }\end{array}$ & Type of workplace mobbing & Authors \\
\hline $\begin{array}{l}\text { Level of } \\
\text { Environment }\end{array}$ & $\begin{array}{l}\text { Mobbing connected to } \\
\text { Socio-demographic characteristics, working conditions and } \\
\text { the level of mobbing }\end{array}$ & $\begin{array}{l}\text { Picakciefe, Acar, Colak } \\
\text { and Kilic, (2015). }\end{array}$ \\
\hline $\begin{array}{l}\text { Individual } \\
\text { Behaviour Level }\end{array}$ & Mobbing resulting from the style of leadership & $\begin{array}{l}\text { Ertureten, Cemalcilar } \\
\text { and Aycan, (2013). }\end{array}$ \\
\hline $\begin{array}{l}\text { Individual Skill } \\
\text { Level }\end{array}$ & $\begin{array}{c}\text { Mobbing as a result of a lack of assertiveness } \\
\text { Mobbing as the result of the lack of social skills interaction } \\
\text { and the social situation }\end{array}$ & $\begin{array}{l}\text { Karakas and Okanli, } \\
\qquad(2015) . \\
\text { Suddaby, Viale and } \\
\text { Gendron, (2016). }\end{array}$ \\
\hline $\begin{array}{l}\text { Values and } \\
\text { Beliefs Level }\end{array}$ & $\begin{array}{c}\text { Mobbing, resulting from attitudes, behavioural intentions, } \\
\text { beliefs }\end{array}$ & $\begin{array}{l}\text { Horvat and Pagon, } \\
(2012) \text {. }\end{array}$ \\
\hline Identity Level & $\begin{array}{l}\text { Mobbing by gender and depression at school: Female stu- } \\
\text { dents use physical force or threat of physical force. Women } \\
\text { could apply gossip, ridicule and social exclusion. }\end{array}$ & $\begin{array}{l}\text { Akinci and Gueven, } \\
\qquad(2015) \text {. }\end{array}$ \\
\hline $\begin{array}{l}\text { Level of Orga- } \\
\text { nizational } \\
\text { Culture }\end{array}$ & $\begin{array}{c}\text { Obsessive passion, well-being and performance at work. } \\
\text { Turnover intention and organizational silence }\end{array}$ & $\begin{array}{l}\text { Birkeland, (2014) } \\
\text { Elci, Erdilek, Alpkan, } \\
\text { and Sener,(2014). }\end{array}$ \\
\hline
\end{tabular}


of the individual in a company. The Model is based on an analysis of selected and current literature about mobbing in companies and an observation of the internal structure of individual mobbing threats.

The findings, that gave us answers to the research questions, are as follows:

The answer to the first exploratory argument: An examination of selected scientific literature and definitions of mobbing allows a better overview of the types of psychological violence in the company and allows for the creation of its typology as follows:

The defined terminology and relationships between concepts increase the understanding of workplace mobbing and allow the creation of mobbing typology depending on its level, and to be able to identify the internal psychological structure of the individual exposed to mobbing.

The answer to the research question: "What type of psychological violence against individuals corresponds to a certain level of mobbing in a company?' is as follows:

We analysed and selected current scientific literature on mobbing between the years 2012 and 2016. Based on this, we presented an expanded Model on levels of mobbing in companies.

Some people perceive mobbing at the level of the environment, as a barrier to their freedom and creative work. A general type of mobbing is connected to social-demographic characteristics, working conditions and the level of mobbing. Micro types of maltreatment are: emotional maltreatment of employees by the management (deliberately influencing the primary and the accompanying emotion), insulting workers, causing guilt, states of anxiety and a dissemination of fear of losing their jobs.

Mobbing at behaviour levels is most evident in the activities and responses of the individual. Based on the analysis of selected literature we exposed a range of mobbing resulting from the style of leadership and management in a company. The most typical forms of mobbing are: Excommunication, undesired influence over workers by the managers, demands for obedience at all costs, and degrading behaviour. Mobbing at the capability levels includes the state and working strategy of the individual. This type of mobbing has a negative effect on the individual's ability to express himself. At this level, there are two main types of mobbing: mobbing due to a lack of decisiveness and mobbing due to poorly developed social skills. Mobbing at the capability level includes the most obvious types of maltreatment: Imposing prohibitions and demands, which start with the word, "No" or "You need to be....", with unrealistic deadlines for completion of work assignments; Whistler punishment.

Mobbing at the level of values and beliefs affect the motivation of the individual.

The most common type of maltreatment at this level is due to a conflict of views, behavioural intentions and restriction of opinions. It is expressed in the following: jealous behaviour, hypocrisy, one-way communication (monologue), which limits free speech with co-workers, religious victimization and sexual harassment in the workplace.

Mobbing at the individual identity level covers the work duties of the organisation. The most common type is the most visible as mobbing, irrespective of gender identity and the degree of depression. Above all, it is present in academic and research fields. This level of mobbing intentionally affects the self-esteem, and occurs in the form of ridicule and humiliation towards the individual.

The highest level and therefore hardly noticeable is mobbing at organizational culture level. General harassment occurring at this level is: an obsessive tendency to feeling good at work and its implementation and intentional organisational silence. In practice, however, at this level the following types of maltreatment are indicated: distrust, social exclusion (ostracism), collective victimization by deliberately organizing conspiracies against undesirable individuals, bribe votes in favour of the management of the company.

The recommendations for the actions: An individual in an firm must be sensitive to the situation of mobbing in the workplace. Using the proposed model individuals or firms can develop preventive measures for protection against those types of mobbing.

\section{Study limitations}

The typology presented in the Model is designed for all those who want to take a deeper look at mobbing or psychological violence in the workplace. The model can also help the employee recognise violence at work and managers at strategic-organisational levels of the company. The adopted Model and types of mobbing in companies has its limitations, as it is built on a theoretical basis of relevant research findings, but could be used as a theoretical basis for an empirical study on mobbing in the company. The types and levels of mobbing at organisational level are an effective tool to alter the behaviour of the individual. However, they should be adapted depending on the type of violence in the workplace. This model represents only a strategic guideline that would be useful to implement the operational plan of protection against mobbing in every work organisation, company or other cooperative.

\section{Literature}

Akinci Z., \& Gueven M., (2015). A study on investigation of the relationship between mobbing and depression, according to genders of high school students. Procedia- Social and Behavioural Sciences, 174, 15971605), http://dx.doi.org/10.1016/j.sbspro.2015.01.810 Arnejčič, B. (2014). Psychological violence and ecology 
of consciousness in the working environment. V: Radivojević, Mladen (ed.). Zbornik radova Univerziteta za poslovne studije Banja Luka. Banja Luka: Univerzitet za poslovne studije. 857-864.

Arnejčič, B. (2013). Socialne veščine otrok in staršev. [Social skills of children and parents]. University of Primorska, Faculty of Education.

Arnejčič, B., \& Hoefler, K. (2008). Courage to undergo education and enter work: (presentation of open model). In: Comparative education, teacher training, education policy and social inclusion. Sofia: Bureau for educational services, 237-243.

Arnejčič. B. (2008). Izbrana poglavja iz psihologije množice, vojaške in vojne psihologije. [Selected Chapters from psychology of crowds, military and war psychology]. University of Ljubljana: Faculty of $\mathrm{Hu}-$ manities.

Birkeland. K. (2014). Fire Walk with Me: Exploring the Role of Harmonious and Obsessive Passion, Well-being and Performance at Work. Oslo: Series of Dissertations, 8/2014: BI Norwegian Business School. Retrieved from http://web.bi.no/forskning/papers. nsf/wSeriesDissertation/D082E9C8C7D67808C1257CF600321E5

Brousse G., Fontana L., Ouchchane L., Boisson, C., Gerbaud, L, Bourguet, D, Perrier, A, Schmitt, A, Llorca, P.M. and Chamoux, A. (2008). Psychopathological features of a patient population of targets of workplace bullying. Occupational Medicine, 58, 122-128, http:// dx.doi.org/10.1093/occmed/kqm148

Cacioppo J., T., and William P. (2008). Loneliness. London: Routledge.

Česen, T. , Darmej, M., Kečanović, B., Modrej, A., Prečnik Posel, S., Posel, F. et al. (2009). Mobbing, trpinčenje, šikaniranje: nekaj usmeritev za pogum pri ohranjanju dostojanstva. [Mobbing, bullying, victimization: some guidelines for their courage in maintaining dignity]. Ljubljana: POGUM-društvo za dostojanstvo pri delu.

Demasio, A. (2008). Looking for Spinoza. Joy, Sorrow, and the Felling brain. [Iskanje Spinoze: veselje, žalost in čuteči možgani]. Ljubljana: Temeljna dela.

Dilts, R. (1990). Changing belief systems with NLP. Capitola: Meta Publications.

Dilts, R., Grindler, J., Bandler, R. \& DeLozier, J. (1980): Neuro-Linguistic Programming. Volume 1, The Study of the Structure of Subjective Experience. Capitola: Meta $\mathrm{Pb}$.

Dilts, R. (1989). Modelling with NLP. Capitola: Meta Pb.

Horvat, K. B., \& Pagon M., (2012). Attitudes toward Workplace Mobbing in Slovenian Research Organisations: Organizacija, 45 (4), 159-173, http://dx.doi. org/10.2478/v10051-012-0018-0

Eurofound, (2009a). EWCO, 'Finland: Increase in workplace bullying over past ten years', 7 December. Retrieved from http://www.eurofound.europa.eu/
ewco/2009/10/FI0910019I.htm

Picakciefe M., Acar G., Colak Z., \& Kilic I., (2015). The Relationship between Socio-demographic Characteristics, and Level of "Mobbing" of Health Workers in Primary Health Care. Journal of Interpersonal Violence, 1-26, http://dx.doi.org/10.1177/0886260515586360

Elci, M. Erdilek K., Alpkan L., \& Sener I. (2014). The Mediating Role of Mobbing on the Relationship between Organisational Silence and Turnover Intention. Procedia-Social and Behavioural Sciences 150, 455-464, http://dx.doi.org/10.1016/j.sbspro.2015.01.110

Ertureten A., Cemalcilar Z., \& Aycan Z., (2013). The Relationship of Downward Mobbing with Leadership Style and Organizational Attitudes. Journal of Business Ethics, 8, (116), 205-216), http://dx.doi.org/10.1007/ s10551-012-1468-2

Facts. (2016). Nasilje na delovnem mestu. [Violence in the workplace]. Facts 24, Evropska agencija za varnost in zdravje pri delu. Retrieved from . http://www.eurofound.europa.eu/ewco/2009/10/FI0910019I.htm

Goodacre, R., \& Zadro, L. 2010. O-Cam: A new paradigm for investigating the effects of ostracism. Behaviour Research Methods, 42, 768-774, http://dx.doi. org/10.3758/BRM.42.3.768

Kirn, A. (2004). Narava, družba, ekološka zavest, [Nature, society, ecological awareness]. Ljubljana: University of Ljubljana, Faculty of Humanities.

Klein, M. (2000). Zavist in hvaležnost. [Envy and gratitude]. Ljubljana: Studia Humanitatis.

Karakas, A. S., Okanli A., (2015). The Effect of Assertiveness Training on the Mobbing that Nurses Experience: Workplace Health \& Safety 10, (446-451), http://dx. doi.org/10.1177/2165079915591708

Lahad, M. (1993). Community stress prevention. Kiryat Shomona: Community Stress Prevention Centre.

Leymann, (1993). Mobbing. Psychoterror am Arbeitsplatz und wie sich dagegen wehren kann, Reinbeck, Rochwolt:Tachenbuch Verlag GmbH.

Leymann, H. (1990). Mobbing and psychological terror at workplaces. Violence and Victims, (35) (1), 119-126.

Leymann, H. (2012). Somatic and psychological symptoms after the experience of life threatening events. A profile analysis. Victimology, $10(1,4), 512-538$, http:// dx.doi.org/10.1080/15555240.2014.866474

Manotas E. M. A. (2015). Mobbing in Organisation: Analysis of Pericular Cases in Higher Educational Institution. Procedia- Social and Behavioural Sciences, 191, 1607-1612, http://dx.doi.org/10.1016/j. sbspro.2015.04.470

O'Reilly, J. Et al. (2014). Negative Attention Better Than No Attention? The Comparative Effects of Ostracism and Harassment at Work. Organisation Science, 4, (774-793), http://dx.doi.org/10.1287/orsc.2014.0900

Waschgler K., Ruiz-Hernández A., H., \& Llor-Esteban B., (2013). Vertical and Lateral Workplace 
Bullying in Nursing: Development of the Hospital Aggressive Behaviour Scale. Journal of Interpersonal Violence, $\mathrm{XX}(\mathrm{X})$ 1-24, http://dx.doi. org/10.1177/0886260513479027

Sunderland M. (2010). The Science of Parenting. [Znanost o vzgoji]. Ljubljana: Didakta.

Suddaby R., Viale T., \& Gendron Y. (2016). Reflexivity: The role of embedded social position and entrepreneurial social skill in processes of field level change. Research in Organizational Behaviour, 88, 0-21, http://dx.doi.org/10.1016/j.riob.2016.02.001

Qureshi, I., M., Iftikhar M., \& Janjua J., S., (2015). Empirical investigation of mobbing, stress and employees' behavior at work place: quantitatively refining a qualitative model, Quela Quant, 49, (93-113), http://dx.doi. org/10.1007/s11135-013-9976-4

Trstenjak, A. (1984). Ekološka psihologija. [Ecological psychology]. Ljubljana: ČGP

Wang, Wenping. (2013). Invisible at Work: An Integrated Model of Workplace Ostracism. Journal of Management, 39, 203-231, http://dx.doi. org/10.1177/0149206312466141

WBI- USA, (2014). Workplace Bullying Survey, February 2014. Retrieved from http://www.workplacebullying. org/wbiresearch/wbi-2014-us-survey/

Williams, D. K. In Nida A., S. (2011). Ostracism: Con- sequences and Coping. Current Directions in Psychological Science 20, 71-75, http://dx.doi. org/10.1177/0963721411402480

Williams, Kipling. (2001a). The Pain of Exclusion, Scientific American Mind, January/February, 2, 29-35.

Williams, Kipling . (2011b). Ostracism: The Power of Silence. New York, London: The Guilford Press.

Zimbardo, P. (2007). The Lucifer Effect, Understanding How Good People Turn Evil, New York: Random House.

Beno Arnejčič graduated in Defence studies at the Faculty of Social Sciences of the Ljubljana University in 1991 and received a doctorate (Ph.D.) in psychology at the University of Ljubljana in 2005. He worked 15 years at the Ministry of Defence for five years as Head of the Centre for Strategic Studies. He worked 5 years at the Ministry of Education as coordinator of the Education and Training 2010 Programme. Since 2010, he has been employed at the Faculty of Education of the Primorska University in Koper. Beno Arnečič is a University lecturer at the Faculty of Education for the following subjects: Sociology of Education, Psychology of organizations, Social skills of children and parents, Dynamics of social groups, Media education, and Learning Environment. 